\title{
APPLICATION OF QUALITATIVE RISK ASSESSMENT TO PRIORITIZE HAZARDS IN PORK PRODUCTS IN BRAZIL
}

\author{
Eduardo de Freitas Costa ${ }^{1}$, Marisa Cardoso ${ }^{2}$, Jalusa Deon Kich ${ }^{3}$, \\ Luis Gustavo Corbellini ${ }^{1}$ \\ ${ }^{1}$ Laboratório de Epidemiologia Veterinária - UFRGS \\ ${ }^{2}$ Laboratório de Medicina Veterinária Preventiva - UFRGS \\ ${ }^{3}$ Embrapa Suínos e Aves
}

\section{Introduction}

The main objective of carcass and meat inspection is to promote animal and public health by controlling and detecting pathogens. (1) Procedures of inspection of pig carcasses in Brazil are based on macroscopic examinations (incisions and palpations) attempting to identify potential hazards to animal and human health, mainly related to classic zoonotic diseases. This inspection structure is based on evidence related to the high relevance of parasites in which transmission and maintenance are strictly linked to the low level of biosecurity measures applied in the farms. (2)

Until 2007 approximately 60\% of Brazilian pork production could be characterized as industrial, adhering to vertical integration systems in which companies have control of management practices, nutrition, technical assistance, increasing the size of herds and complexity of the chain. (3) If in one hand the industrial production reduces the release of parasites and classic zoonosis, on the other hand, microscopic hazards with no clinical signs or macroscopic lesions are arising.

There is a distance between the structure of industrial pig herds in Brazil and the procedures of inspection of pig carcasses, bringing some skepticism about how suitable the inspection procedures are in promoting public health. To attempt for this new reality, adequacy of a monitoring system must be based in a rational and transparent way. (4)

Risk assessment (RA) is a step of risk analysis being usually referred between the risk management and risk communication. In food safety context RA can be defined as a process of scientific considerations and data collection in a structured way following the production flow assisting the understanding of risks and adverse effects resultant of exposure to hazards present in food. Thus RA aids risk managers to apply strategies to promote public health, taking into account different epidemiological realities and complex relationship between different steps of production and its uncertainties. (5)

In this sense, this work aims to describe the application of a qualitative risk assessment to prioritize hazards in Brazilian industrial pork production and highlight the adequacy of the current inspection of pig carcasses in Brazil.

\section{Material and methods}

The model adopted was the one from Codex Alimentarius (CAC/GL 2007) (6) with four steps: I) hazard identification; II) hazard characterization; III) exposure assessment and IV) risk characterization. The interaction between different dimensions in this model followed the matrix in Table 1. 
Table 1. Qualitative matrix used to interact with the different dimensions in the model.

\begin{tabular}{lllllll}
\hline \multicolumn{5}{c}{$\mathbf{2}^{\mathbf{0}}$ Dimension } \\
\hline $\mathbf{1}^{\mathbf{0}}$ Dimension & $\mathbf{1}$ & $\mathbf{2}$ & $\mathbf{3}$ & $\mathbf{4}$ & $\mathbf{5}$ \\
\hline $\mathbf{1}$ & 1 & 1 & 1 & 1 & 1 \\
$\mathbf{2}$ & 2 & 2 & 2 & 2 & 3 \\
$\mathbf{3}$ & 2 & 2 & 3 & 4 & 4 \\
$\mathbf{4}$ & 3 & 3 & 4 & 4 & 5 \\
$\mathbf{5}$ & 3 & 4 & 4 & 5 & 5 \\
\hline
\end{tabular}

A systematic review approach was used in hazard identification step using the keywords: ("bacterial agents OR viral agents OR fungal agents OR parasitic agents") AND ("swine OR pork OR pig"). Searches were done in January 2015 in Portuguese and English in PubMed, ScienceDirect, ISI and Web of Science. Abstracts of events such as SafePork and IPVS and hazards already described in Brazilian legislation were also included.

To be considered as relevant each hazard should answer YES to the following three questions: 1) Can the hazard be responsible for an infection/intoxication in human beings through the pork consumption?; 2) Is the hazard present in Brazilian industrial herds?; 3) Is the hazard introduced by slaughter and dressing activities?

Hazard characterization was done using information about pathogenicity and magnitude of the adverse effects of each hazard. Exposure assessment was the probability of ingestion of the hazards by pork consumption and takes into account the whole production. The conceptual model considers the interaction between the level of presence of the hazard in the herds/animals (called "initial presence") and probabilities of reduction and amplification along the process. Hence, exposure assessment was modeled sequentially as: initial presence*amplification*reduction of the hazard. A baseline scenario was modeled to non-processed pork and two different scenarios regarding cooked and fermented products were also made.

Risk characterization is the interaction between exposure and hazard characterization and refers to the probability of occurrence (i.e. exposure $\mathrm{x}$ pathogenicity) of foodborne disease by pork consumption associated with the adverse effects, and was described in five levels: 1) risk is very low; 2) risk is low; 3) risk is moderate; 4) risk is high; 5) risk is very high.

\section{Results and discussion}

One hundred twenty four hazards were indentified of which 88 were excluded because the transmission does not occur through pork meat. Of 36 remaining, 14 were excluded for not being present in the population in the past 20 years and two were included because of the potential contamination during slaughter processing. At the end, 24 hazards were included: $66.6 \%$ were bacterial, $20.8 \%$ parasites, $12.5 \%$ toxins or virus.

There were no hazards characterized as very high risk [5] and Salmonella sp. was classified as high risk [4]. Salmonella figured as the highest hazard among those identified for non-processed pork. Parasites had risk characterized as very low [1] or low [2] in non-processed pork but there are uncertainties regarding the pathogenicity and adverse effects of these hazards. The risk rank of hazards for non-possessed pork (baseline scenario) is demonstrated in Figure 1. 


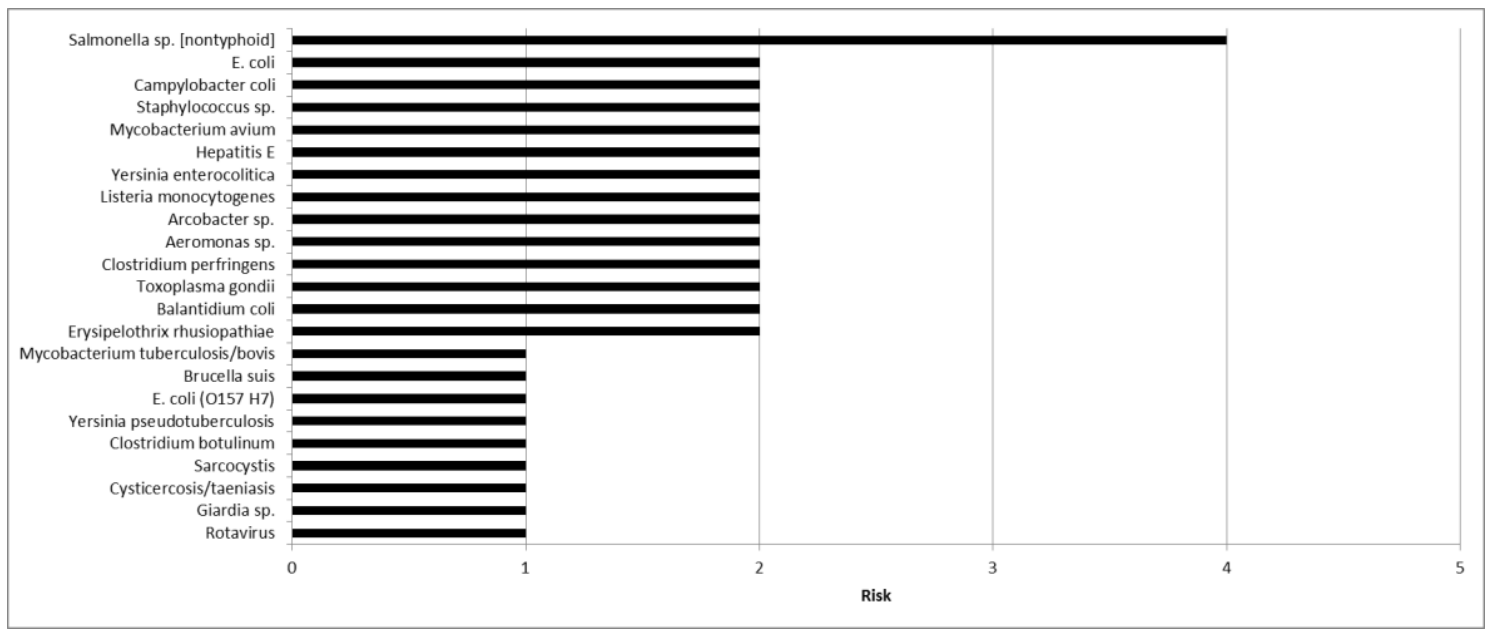

Figure 1. Risk characterization of the identified hazards related to the consumption of non-processed pork.

For cooked products, the thermal resistance of both spores of Clostridium perfringens and Ochratoxin A (OTA) increased their risks to high [4]. OTA is only accounted in the model when kidneys are included in the product (i.e. scenario of cooked products), and uncertainties associated to OTA are very high, including for the presence in Brazilian herds, pathogenicity, and adverse effects. Therefore, more information is needed to an accurate characterization of risk for this hazard. Furthermore, the heat reduces the risk of Salmonella sp. to moderate [3] in these products.

For fermented products, none hazards were classified as very high risk [5], and Salmonella sp. was classified as high [4], followed by Staphylococcus aureus, Escherichia coli, Clostridium perfringens and Campylobacter coli with moderate risk [3]. The effect of bacterial reduction in fermented products (by $\mathrm{pH}$ variation or water activity reduction) can be faced as conservative and according to several authors more than inhibition of bacterial growth, there is an actual reduction in the number of cells. Anyway, considering fermentation, Salmonella sp. was kept in high risk [4].

Regarding the model sensitivity, the initial presence of the hazards had the highest impact in the overall risk characterization. When the prevalence is increased the risk profile shifts from bacterial to parasitic, and the lasts reach high risk [4] and Clostridium botulinum reaches very high risk [5] for non processed pork.

\section{Conclusion}

The hazards characterized as high risk in non-processed, cooked and fermented pork are mainly bacterial, with a complex cycle, and rarely affecting clinically pigs with no macroscopic lesions. In this sense, macroscopic examinations of carcasses are no longer adequate to account for the main zoonotic hazards in Brazilian industrial pork production bringing the need to quantitative modeling, to identify critical points to control microscopic hazards keeping then in strict statistical control and applying corrective procedures when necessary. 


\section{References}

1. OIE. Control of biological hazards of animal health and public health importance through ante and post-mortem meat inspection. In: Terrestrial Animal Health Code [Internet]. 24th ed. Paris: World Organization for Animal Health (OIE); 2015 [cited 2015 Nov 10]. Available from: http://web.oie.int/eng/normes/mcode/en_chapitre_1.6.2.pdf.

2. Brasil. Portaria $\mathrm{N}^{\mathrm{O}} 711$, de $1^{\mathrm{o}}$ de Novembro de 1995 [Internet]. Brazil: Ministerio da Agricultura Pecuária e Abastecimento (MAPA); 1995 p. 98. Available from: http://www.agricultura.gov.br/arq_editor/file/Ministerio/concursos/em_andamento/portarias/port 711.doc.

3. Miele M. Levantamento Sistemático da Produção e Abate de Suínos. Embrapa Suínos e Aves. 2006;550(104):27.

4. Commission Regulation (EU) No 219/2014 of 7 March 2014 amending Annex I to Regulation (EC) No 854/2004 of the European Parliament and of the Council as regards the specific requirements for post-mortem inspection of domestic swine. Text with EEA relevance. 2014. p. 99-100.

5. FAO. Risk-based food inspection manual. [Internet]. Vol. 89, FAO Food and Nutrition Paper 89. Rome: Food and agriculture organization of the united antions; 2008. 1-85 p. Available from: ftp://ftp.fao.org/docrep/fao/010/i0096e/i0096e00.pdf.

6. Cac/Gl 63-2007. Principles and guidelines for the conduct of microbial risk management (MRM). Codex Aliment. 2007;1-19. 